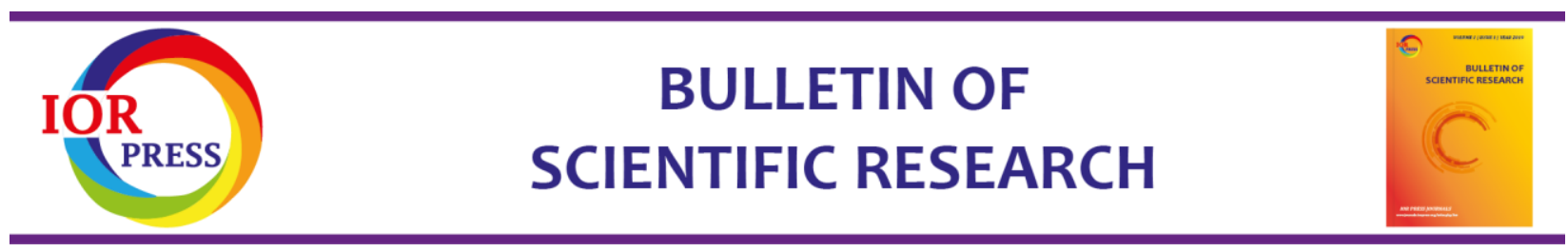

\title{
Drying of washed clothing utilizing solar powered dryer
}

\section{R.V. Romero a, ${ }^{*}$, N.V. Romero ${ }^{\text {a }}$}

a College of Engineering and Technology, Partido State University, Goa, Camarines Sur, Philippines.

*Corresponding Author: munding25@yahoo.com.ph DOI: https://doi.org/10.34256/bsr2114

Received: 12-01-2021

Accepted: 07-02-2021

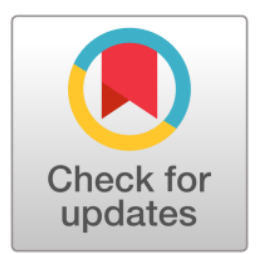

\begin{abstract}
This study made setups that can be used in solar powered drying of washed clothing. This was used to analyze and test the performance, and determined if there is significant difference on the drying rate of set ups related to traditional and experimental method. A solar drying chamber was designed to use local materials in which the frame is made of bamboo with walls made of plastic to trap the heat of the sunlight entering the chamber. There were four set ups that were established in the gathering of data: S-1 is with electric fan, S2 is with electric fan and electric flat iron, S-3 which did not use the drying chamber, is a traditional method where the garments C-1, C-2, C-3, C-4 \& C-5 of different sizes, shapes, width and weight were dried under the heat of the sun. S-4 is almost similar to S-3 but the difference is that the garments were dried with no sunlight. The drying chamber alone is effective to reduce the moisture content of the garments using sunlight. Using the electric fan and electric flat iron increased the circulation of the enclosed hot air and boasted the drying capacity. Although it was computed that $\mathrm{P}>\alpha$ in comparison of the data in all set ups, it is insufficient to conclude that there is no significant difference on data of the experimental and traditional set ups since the data for the traditional set ups are not complete until the garments are totally dried.
\end{abstract}

Keywords: Solar Power, Dryer, Drying Chamber, Post-Harvest Agriculture

\section{Introduction}

Drying reduces moisture content which involves the concept of heating with the passage of quantity of air to move away the released vapor. It is the process of removing moisture from the dried materials under the natural or manual conditions using several methods like using of microwave, vacuum, freeze and heat pump. However, hot air-drying technology obtains the advantages for it is a kind of traditional drying method that uses the heated air as the drying medium and transfers heat to the wet materials thru heat conduction effect [1] The system which usually consists of the heating element, blower, drying chamber and heating chamber [2] performed better if the drying time is compared using direct sundrying and refrigerator drying.

There is existing stud is on drying of washed clothes using solar power. Among them is a device consisting of insulation shell, good heat transfer system, ventilation system, drainage system, temperature humidity control system, ultraviolet radiation, sterilization disinfection system and other auxiliary system that achieve better results than clothes that are dried outside the window [3]. The solar cloth dryer of accomplished a normal drying rate of $0.35 \mathrm{~kg} . \mathrm{h}$ and drying time of 3 hours even at moderate open air wind speed [4]. Clothes lines 
and other hang drying methods subjected users to a lack of privacy, extremely long drying time and great dependency on weather but with the development of the solar clothes dryer was able to provide a solution through faster drying time, low cost and superior energy efficiency [5] On the other hand, a mathematical model was derived representing solar cloth dryer with an analysis of the elements necessary for successful designing of the various components of a solar dryer which shows good agreement between the computational solid simulation and the experimental measurements obtained from the [6]. It's better if the whole set up is made easily from existing materials and since solar dryer is a closed chamber, dirt from outside can hardly impact the pieces of clothing which will result in a uniform, spotless and gainful drying Solar cloth dryer designed with two processes such as dehumidified air inlet process and humid air outlet process consisting of heat exchangers, fans and a desiccant wheel was able to remove $1.7439 \mathrm{~kg}$ of moisture content within 9.65 minutes in which the assumptions and calculation were based on thermodynamics principles and [7].

The main objective of this study is to analyze setups that can be used in solar powered drying of washed clothing. Specifically, it aims to design a system by which solar powered dryer may be applied in drying of washed clothing; to analyze and test the performance; and to determine if there is significant difference on the drying rate of set ups related to traditional and experimental method of drying.

\section{Methods}

Guided by the natural convection method of drying, a drying chamber and several set ups were made on this study.

\subsection{The experimental set ups}

A solar drying chamber was designed to use local materials in which the frame is made of bamboo. The wall of the drying chamber is made of plastic to trap the heat of the sunlight that enter the chamber. The length of the chamber is 1.05 meters, width is 0.50 meters, height of the body is 1.10 meter but with roof included the height is 1.28 meters. It is inside the chamber where wet clothing was dried. On the first set up (S-1), an electric fan with frame made up of bamboo is attached on the chamber with the purpose that the hot air trapped on the chamber would continuously circulate around the wet clothing. The motor of the electric fan is 12 volts and 18 watts (See Figure 1).

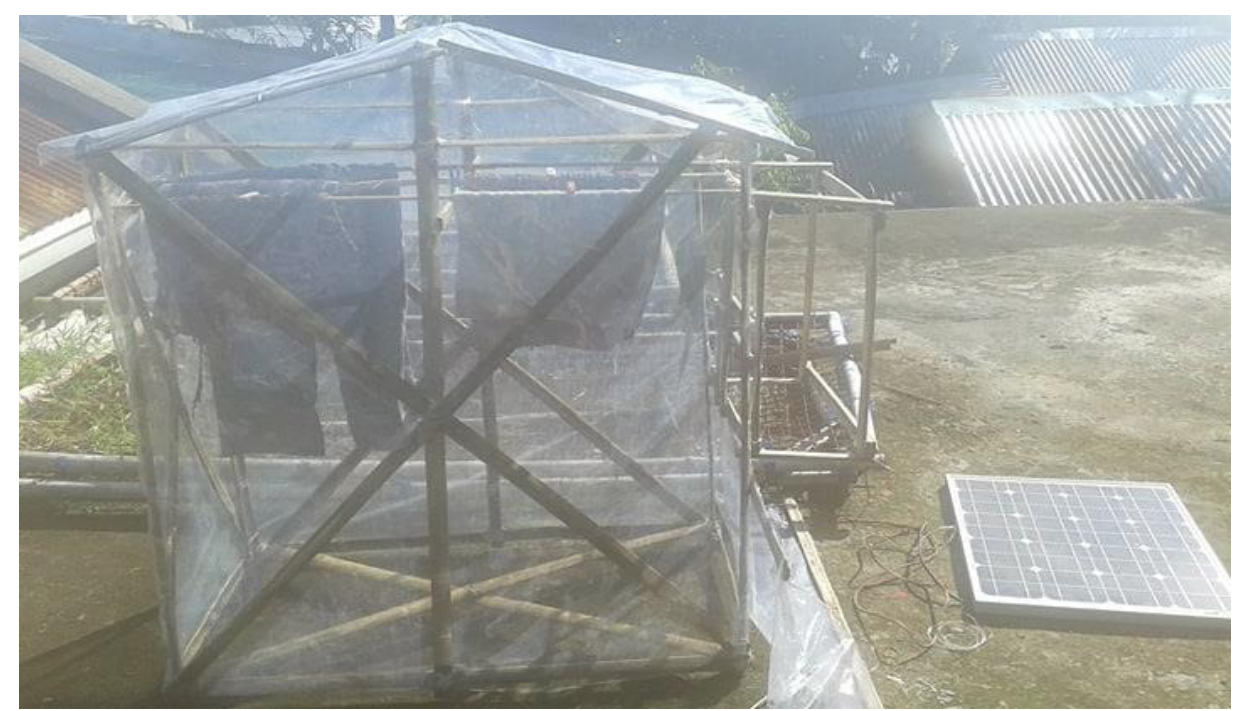

Figure 1. The experimental set up (S-1) showing the drying chamber, electric fan, washed clothes and the solar panel 


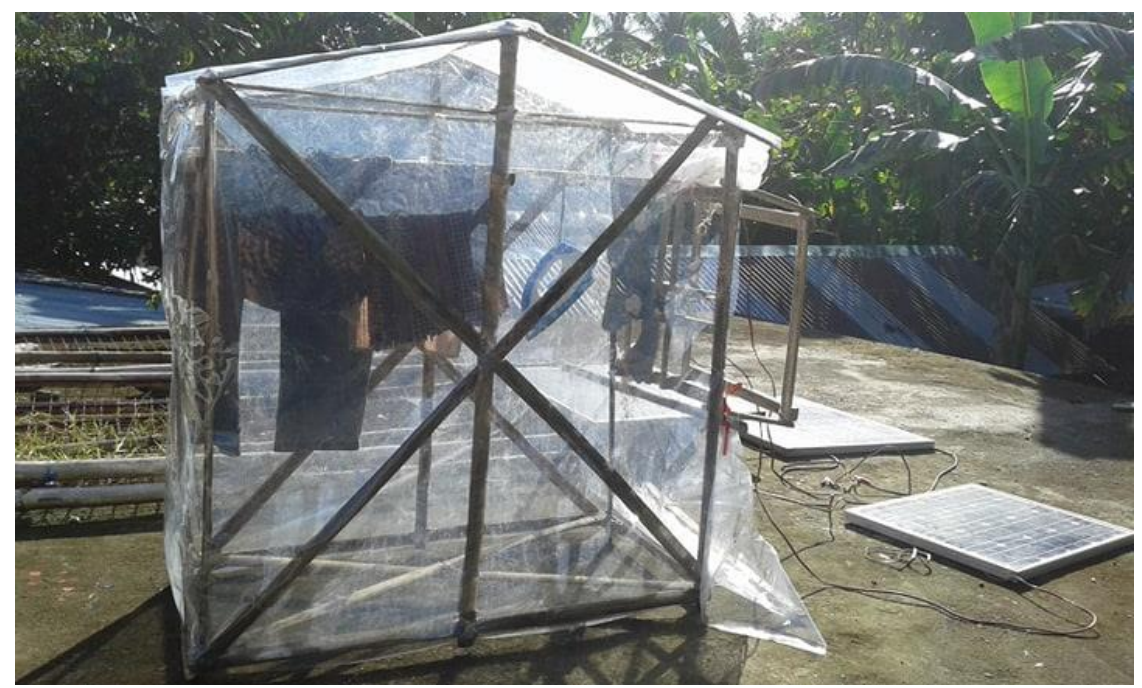

Figure 2. The experimental set up (S-2) showing the drying chamber, electric fan, washed clothes and the solar panel

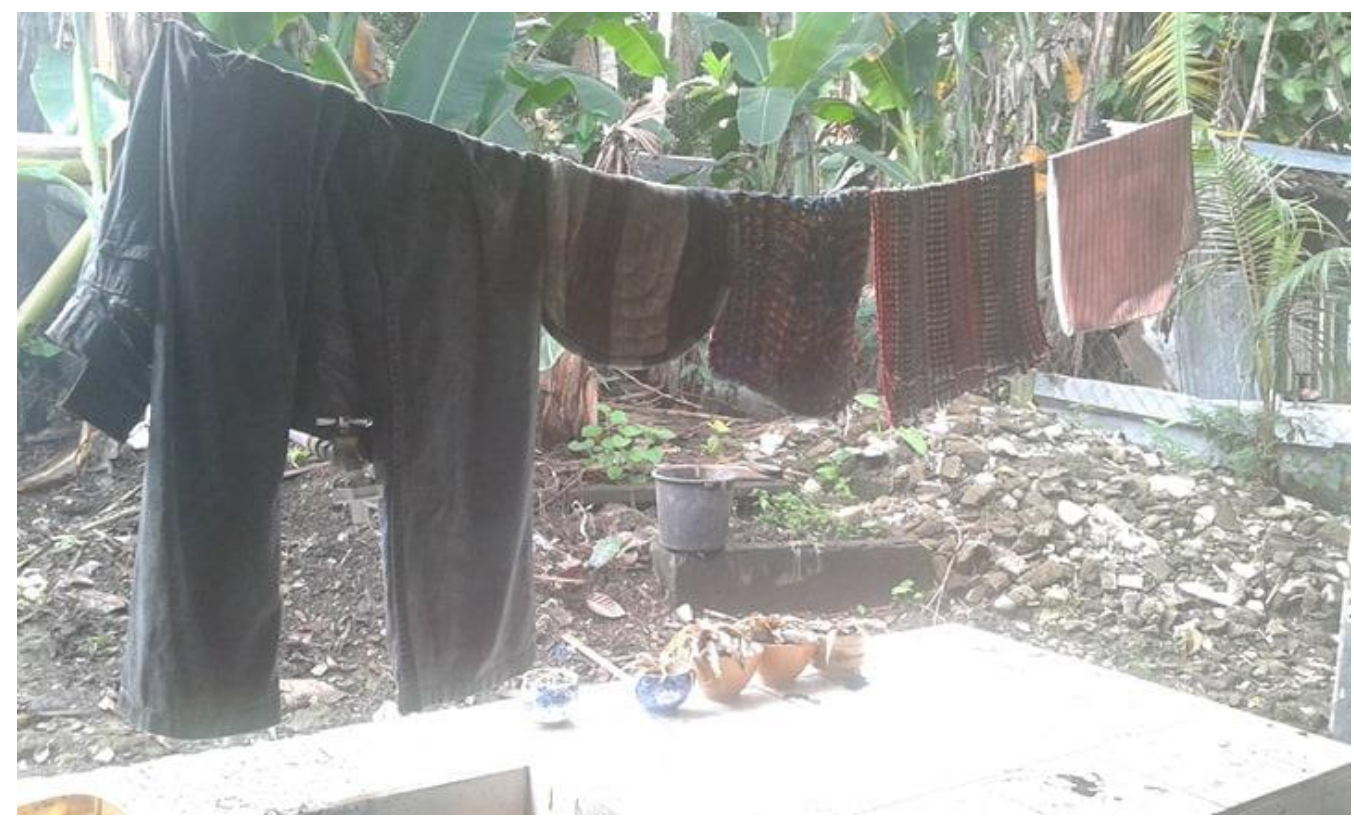

Figure 3. The experimental set up (S-3) showing the garments dried under the heat of the sun without using of the drying chamber, electric fan, solar panel and electric iron.

On the second set up (S-2), an electric flat iron was attached in front of the electric fan to amplify the heat. With the electric fan, hot air would continuously circulate inside the chamber. The electric flat iron is 12 volts and 150 watts. The electric flat iron is connected directly to 200 watts solar panel while the electric fan was connected directly to a 50 watts solar panel (See Figure 2).

Set up $3(S-3)$ is a control set up in which the clothes were dried in a typical way by drying under the heat of the sun without using the chamber, electric fan, solar panel and electric iron (See Figure 3).

Set up $4(\mathrm{~S}-4)$ is similar to $\mathrm{S}-3$ except that the garments are not exposed under the heat of the sun without drying chamber, electric fan, solar panel and electric iron. The garments used are composed of the following: The first cloth (C-1) is a rectangular absorbent cloth which was used as rug with size of $36 \mathrm{~cm} \times 55 \mathrm{~cm} \times 1 \mathrm{~mm}$. The weight of this cloth 
when dried is $0.01 \mathrm{Kg}$. The second cloth $(\mathrm{C}-2)$ is a $30 \mathrm{cmX} 36 \mathrm{cmX} 4 \mathrm{~mm}$ rectangular rug that when dried is weighing $0.2 \mathrm{~kg}$. The third cloth $(\mathrm{C}-3)$ is a $36 \mathrm{~cm} \times 55 \mathrm{~cm} \times 4 \mathrm{~mm}$ rectangular rug in which when dried is weighing $0.30 \mathrm{~kg}$; the fourth cloth (C-4) is a rug with oval shape and width of $31 \mathrm{~cm}$, length of $43 \mathrm{~cm}$, thickness of $5 \mathrm{~mm}$ and dry weight of $0.40 \mathrm{~kg}$. The fifth cloth $(\mathrm{C}-5)$ is a long jean pant with width of $46 \mathrm{~cm}$, length of $51 \mathrm{~cm}$, thickness of $3 \mathrm{~mm}$ and dry weight $0.45 \mathrm{~kg}$.

\subsection{The data collection process}

The collected data were based on the moisture contents of the washed clothes after they were exposed to drying for several hours. Using the four set ups the moisture of the washed clothes were measured in hourly basis after the set ups were prepared.

\subsection{Treatment of data}

Significant difference on the computed data were determined using ANOVA and t-test. The statistical tools were used to prove the following null hypothesis: is there a significant difference on the following: $S-1$ versus $S-2, S-2$ versus $S-3, S-3$ versus $S-1, S-4$ versus $S-2, S-4$ versus $S-1, S-4$ versus $S-3$, and $S-1$ versus $S-2$ versus $S-3$ versus $S-4$ versus $S-5$.

\section{Results and Discussion}

\subsection{The designed system}

The designed system was based from the idea that direct solar and ventilation gains are two crucial parameters that should be taken to design an enclosed cloth solar dryer According to [8, 9], A temperature-controlled chamber is based on the natural chamber principle utilizing pressure, temperature, humidity and moisture. Hence, the design of this solar cloth dryer is an enclosed chamber made of plastic that five to fifteen number of clothes could be dried. The frame of the cloth dryer is made of bamboo.

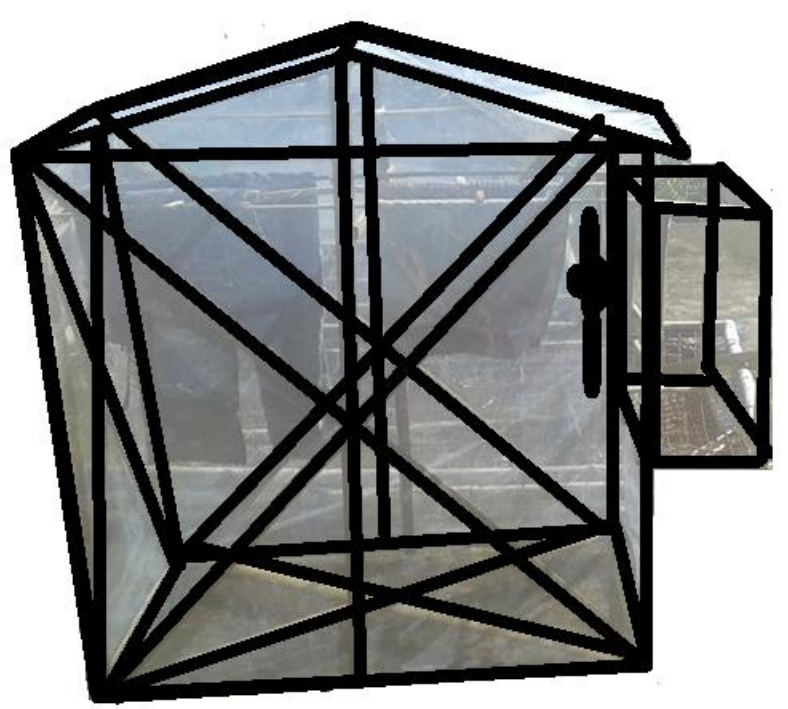

Figure 4. The designed solar powered dryer

Enclosure of the chamber with plastic does not allow the ray of sunlight to escape making the temperature inside higher as the enclosed sunlight reflect inside. Supplying the chamber with an electric fan increased the circulation of the enclosed hot air and boasted the drying capacity. The electric flat iron was supplied to reinforce the enclosed temperature making the drying capacity higher. Using solar energy makes the operation of the drying chamber free which is opposite on the findings of [10]. that conventional temperature and humidity chambers comprising of air circulating fans, refrigerator unit, electric heater and humidifier consumes much energy during the operation. Figure 4 shows the designed solar powered dryer.

\subsection{The observed moisture content for} S-1.

It was observed that $\mathrm{C}-1$ was dried within three hours, C-2, C-4 and C-5 were dried within four hours while C-4 contains $10 \%$ of moisture content (Table 1 ).

The data reveals that using air circulating fan reduced the moisture content of the garments. The data also reveals that the drying rate on each different kind of garments varies and are increasing. Air circulation through the electric fan may increase airflow 
that eventually improve drying rate since airflow carry away moisture [11].

Table 1. Moisture content after hours of drying on $\mathrm{S} 1$

\begin{tabular}{|c|c|c|c|c|c|}
\hline \multirow{2}{*}{$\begin{array}{c}\text { Cloth } \\
\text { No. }\end{array}$} & \multicolumn{5}{|c|}{ Drying time (Hours) } \\
\cline { 2 - 6 } & 0 & 1 & 2 & 3 & 4 \\
\cline { 2 - 6 } & \multicolumn{5}{|c|}{ Moisture content (\%) } \\
\hline C-1 & 2000 & 1000 & 100 & 0 & 0 \\
\hline C-2 & 250 & 200 & 125 & 50 & 0 \\
\hline C-3 & 133.33 & 100 & 83.33 & 50 & 0 \\
\hline C-4 & 100 & 50 & 37.5 & 25 & 10 \\
\hline C-5 & 100 & 55.56 & 44.44 & 33.33 & 0 \\
\hline Mean & 516.67 & 281.11 & 78.05 & 31.67 & 2.0 \\
\hline
\end{tabular}

\subsection{Observed moisture content for $S-2$}

It was observed that $\mathrm{C}-1$ was dried within three hours, C-2, C-4 and C-5 were dried within four hours while C-4 on that time contains $12.5 \%$ of moisture content. The situation is almost similar with S-1 (Table 2).

Table 2. Moisture content after hours of drying on S-2

\begin{tabular}{|c|c|c|c|c|c|}
\hline \multirow{2}{*}{$\begin{array}{c}\text { Cloth } \\
\text { No. }\end{array}$} & \multicolumn{5}{|c|}{ Drying time (hours) } \\
\cline { 2 - 6 } & 0 & 1 & 2 & 3 & 4 \\
\cline { 2 - 6 } & \multicolumn{5}{|c|}{ Moisture Content (\%) } \\
\hline C-1 & 2400 & 1,400 & 100 & 0 & 0 \\
\hline C-2 & 225 & 205 & 100 & 90 & 0 \\
\hline C-3 & 150 & 133.33 & 100 & 40 & 0 \\
\hline C-4 & 87.50 & 75 & 50 & 25 & 12.5 \\
\hline C-5 & 144.44 & 77.78 & 33.33 & 11.11 & 0 \\
\hline Mean & 601.34 & 378.22 & 76.67 & 33.22 & 2.5 \\
\hline
\end{tabular}

The data reveals that using air circulating fan and flat iron as heat pump and temperature enhancer reduced the moisture content of the garments. The data also reveals that the drying time on each different kind of garments varies and are increasing. [12] Exposed that using fans inside the greenhouse helps the air to circulate and mix, giving rise to a more homogeneous inside temperature that increased the average value of normalized air velocity by $365 \%$ and increased the average values of kinetic turbulence energy inside the greenhouse by $550 \%$ compared to conditions of natural ventilation. The open and semi-open heat pump dryers could be greatly affected by ambient temperature and humidity while the closed heat pump drying system could be greatly affected by the bypass air rate [13].

\subsection{The observed moisture content for S-3.}

It was observed that $\mathrm{C}-1$ was dried within three hours while C-5 were dried within five hours while $\mathrm{C}-2$ on that time contains $115 \%$ of moisture content, C-3 has $33.33 \%$ and C-4 has 5.0\% (Table 3).

The data reveals that the drying rate on each different kind of garments varies and are increasing. The data shows that using the heat of the sun as the conventional method reduced the moisture content, however it takes longer time to dry the garments as compared to the drying chamber with fan and electric flat iron (Table 4-6).

Table 3. Drying time and moisture content on S-3

\begin{tabular}{|c|c|c|c|c|c|c|}
\hline \multirow{3}{*}{ Cloth No. } & \multicolumn{7}{|c|}{ Drying time } \\
\cline { 2 - 7 } & 0 & 1 & 2 & 3 & 4 & 5 \\
\cline { 2 - 7 } & \multicolumn{7}{|c|}{ Moisture content (\%) } \\
\hline C-1 & 1900 & 900 & 400 & 100 & 0 & 0 \\
\hline C-2 & 200 & 195 & 180 & 170 & 125 & 115 \\
\hline C-3 & 110.00 & 93.33 & 80 & 73.33 & 66.67 & 33.33 \\
\hline C-4 & 55 & 50 & 35 & 25 & 12.5 & 5 \\
\hline C-5 & 122.22 & 77.77 & 68.89 & 55.56 & 22.22 & 0 \\
\hline Mean & 477.44 & 263.22 & 152.78 & 84.78 & 45.28 & 30.67 \\
\hline
\end{tabular}


Table 4. Drying time and moisture content on S-4

\begin{tabular}{|c|c|c|c|c|c|c|c|c|}
\hline \multirow{2}{*}{ Cloth No. } & \multicolumn{10}{|c|}{ Drying time } \\
\cline { 2 - 9 } & 0 & 1 & 2 & 3 & 4 & 5 & 6 & 7 \\
\hline C-1 & 2400 & 1900 & 1800 & 1700 & 1400 & 900 & 8 & 0 \\
\hline C-2 & 290 & 285 & 280 & 270 & 250 & 200 & 190 & 185 \\
\hline C-3 & 183 & 1.66 .67 & 163.63 & 160 & 133.33 & 116.67 & 110 & 106.67 \\
\hline C-4 & 112.5 & 100 & 97.5 & 95 & 75 & 62.5 & 55 & 50 \\
\hline C-5 & 166.67 & 162,22 & 144.44 & 120 & 88.89 & 77.77 & 66.67 & 62.22 \\
\hline Mean & 630.43 & 522.78 & 497.11 & 469 & 389.44 & 271.39 & 85.93 & 80.78 \\
\hline
\end{tabular}

Table 5. Reduction rate of moisture content per hour of drying.

\begin{tabular}{|c|c|c|c|c|}
\hline \multirow{2}{*}{$\mathrm{T}$} & \multicolumn{5}{|c|}{ Setups } \\
\cline { 2 - 5 } & $\mathrm{S}-1$ & $\mathrm{~S}-2$ & $\mathrm{~S}-3$ & $\mathrm{~S}-4$ \\
\hline 1 & 235.56 & 232.12 & 214.22 & 107.65 \\
\hline 2 & 203.06 & 301.45 & 110.44 & 25.67 \\
\hline 3 & 46.38 & 43.45 & 68 & 28.11 \\
\hline 4 & 29.67 & 30.72 & 39.5 & 79.56 \\
\hline 5 & 0 & 0 & 14.61 & 118.05 \\
\hline 6 & 0 & 0 & 0 & 185.46 \\
\hline 7 & 0 & 0 & 0 & 5.15 \\
\hline Mean & 128.67 & 151.94 & 89.35 & 52.03 \\
\hline
\end{tabular}

Table 6. Significant difference on data of different set ups

\begin{tabular}{|c|l|l|}
\hline Parameters & Computation Result & Decision \\
\hline S-1 VS S-2 & $\mathrm{P}=0.41>\alpha=0.05$ & Cannot reject the hypothesis \\
\hline S-2 VS S-3 & $\mathrm{P}=0.23>\alpha=0.05$ & Cannot reject the hypothesis \\
\hline S-3 VS S-1 & $\mathrm{P}=0.28>\alpha=0.05$ & Cannot reject the hypothesis \\
\hline S-4 VS S-2 & $\mathrm{P}=0.19>\alpha=0.05$ & Cannot reject the hypothesis \\
\hline S-4 VS S-1 & $\mathrm{P}=0.21>\alpha=0.05$ & Cannot reject the hypothesis \\
\hline S-4 VS S3 & $\mathrm{P}=0.40>\alpha=0.05$ & Cannot reject the hypothesis \\
\hline S-1 VS S-2 VS S3 VS S4 & $\mathrm{P}=0.60>\alpha=0.05$ & Cannot reject the hypothesis \\
\hline
\end{tabular}

\subsection{The observed moisture content for} S-4

It was observed that $\mathrm{C}-1$ was dried within seven hours of drying while C-5 are still containing large amount of moisture content.

The data reveals that the moisture content was reduced in conventional setup with no sunlight but the drying time is delayed compared to the other set ups. Among the disadvantages of the traditional method of sun drying is when it totally depends on good weather conditions [14].

\subsection{Reduction rate of moisture content}

The table shows that S-2 has highest reduction rate at 151.94 , followed by $\mathrm{S}-1$ at 128.67 and $\mathrm{S}-3$ at 89.53 while is the lowest S-4 at 52.03

The data reveals that using an electric fan with electric flat iron was effective to increase the reduction rate of the moisture content. Utilizing air velocity of air stream circulation and medium or high temperature in the process may result in a product of superior quality compared to products dried by solar dehydration [15]. 


\subsection{Significant difference on data of different set ups.}

The table shows that the null hypotheses cannot be rejected for $\mathrm{P}>\alpha$ on the following investigation: S-1 VS S-2, S-2 VS S-3, S-3 VS S-1, S-4 VS S-2, S-4 VS S-1, S-4 VS S-3 and S-1 VS S-2 VS S-3 VS S-4.

Although the computed data reveals that there are no significant differences on the data between different set ups, the result could not be the bases to prove that there is no significant difference on the performance of drying on set ups where the traditional and the experimental methods were applied. The investigated data are limited only at certain hours that the garments on experimental method were dried and not to the point that all the garments used particularly on the traditional set ups were totally dried.

\section{Conclusion}

The solar cloth dryer made on this study is an enclosed chamber made of plastic. with frame made of bamboo. Enclosure of the chamber with plastic prevents the ray of sunlight to escape as the enclosed sunlight reflected inside. This increased the temperature inside the chamber. The drying chamber alone is effective to reduce the moisture content of the garments using sunlight but with an electric fan and electric flat iron increased the circulation of the enclosed hot air and boasted the drying capacity. Although it was computed that $\mathrm{P}>\alpha$ in comparison of data in all the set ups, it is insufficient to conclude that there is no significant difference on data of the experimental and traditional set ups since the data for the traditional set ups are not continued until all the garments used are totally dried. The study could be replicated on drying of agricultural and fishery products using the designed chamber. 


\section{References}

[1] Ran Zhao, Tianhao Gao, Research progress of hot airdrying technology for fruits and vegetables, Advance Journal of Food Science and Technology, 10 (2016) 160-166. http://dx.doi.org/10.19026/ajfst.10.2045

[2] S.A. Aasa, 0.0. Ajayi, O.A. Omotosho, Design optimization of hot air dryer for yum flour chunk, Asian Journal for Scientific Research, 5 (2012) 143-152. https://dx.doi.org/10.3923/ajsr.2012.143.152

[3] J. Wu, L. Zhao, N. Xie, L. Gao, W.Gao, X. Dai, J. Zhang, Research on the characteristics of a novel solar drying system and its application, Energy Procedia, 14 (2012) 399-404, https://doi.org/10.1016/i.egypro.2011.12.949

[4] D. S. Kirar, H. S. Bhadoria, R. Pandey, Configuration and Development of a Solar Cloth Dryer, In MATEC Web of Conferences, 57 (2016) 1-5. DOI: http://dx.doi.org/10.1051/matecconf/20165701019

[5] S.O. Amiebenomo, I.I. Omorodion, J.O. Igbinobaq, Prototype design and performance analysis of solar clothes dryer, Asian Review of Mechanical Engineering, 2 (2013) 35-43.

[6] A. Alahmer, M. Al-Dabbas, Design and construction of a passive solar power clothing dryer, Research Journal of Applied Sciences, Engineering and Technology, 7 (2014) 2785-2792. DOI: 10.19026/rjaset.7.60.

[7] Celil May R. Ylagan, Design of solar desiccant clothes dryer, International Journal of Engineering and Techniques, 3 (2017) 189-194.

[8] Alahmer, Ali, Al-Dabbas, Mohaammed, Design and construction of a passive solar power clothing dryer, Research Journal of Applied Sciences, Engineering and Technology, 7 (2014) 2785-2792. DOI: https://doi.org/10.19026/rjaset.7.600

[9] Ezike, Sebastine Chinadu, Alabi, Aderemi Babatunde, Ossai, Amarachuckwu Nneka \& Aina, Adebayo Olanivi, A low-cost temperature-controlled chamber fabricated for materials testing, Designs, 2(2018) 1-10. https://doi.org/10.3390/designs2030025

[10] K. Mensah, J. M. Choi, Energy consumption and stability investigation of constant temperature and humidity test chamber, International Journal of Air-Conditioning and Refrigeration, 25 (2017) 1-11. https://doi.org/10.1142/S2010132517500109

[11] J. Lee, N. Hoeller, D. Rogers, S. Musnier, F. A. Salustri, (2009) An empirical study of energy efficiency of clothes dryers, In DS 58-7: Proceedings of ICED 09, the 17th International Conference on Engineering Design, 7 (2009) 253-264.

[12] A. López, D. L. Valera, F. D. Molina-Aiz, A. Peña, (2013) Effectiveness of horizontal air flow fans supporting natural ventilation in a Mediterranean multi-span greenhouse, Scientia Agricola, 70 (4) 219-228. DOI: https://doi.org/10.1590/s0103-90162013000400001

[13] H. Liu, K. Yousaf, K. Chen, R. Fan, J. Liu, S. A. Soomro, Design and thermal analysis of an air source heat pump dryer for food drying, Sustainability, 10 (2018) 1-17. DOI: https://doi.org/10.3390/su10093216 
[14] C. B. Pardhi, J. L. Bhagoria, Development and performance evaluation of mixed-mode solar dryer with forced convection, International journal of energy and environmental engineering, 4 (2013) 1-8. https://doi.org/10.1186/2251-6832-4-23

[15] V.T. Karathanos, V.G. Belessiotis, Sun and artificial air-drying kinetics of some agricultural products, Journal of Food Engineering, 31 (1997) 35-46. https://doi.org/10.1016/S0260$\underline{8774(96) 00050-7}$

\section{Acknowledgement}

NIL

\section{Funding}

This study was not funded by any grant

\section{Conflict of interest}

None of the authors have any conflicts of interest to declare.

\section{About the License}

(C) The author(s) 2021. The text of this article is open access and licensed under a Creative Commons Attribution 4.0 International License 